\title{
Hall Thruster Thermal Modeling and Test Data Correlation
}

\author{
Presented at the American Institute of Aeronautics and Astronautics, \\ Propulsion and Energy Conference, Salt Lake City, Utah July 25-27, 2016 \\ James Myers ${ }^{1}$, Hani Kamhawi², John Yim³ ${ }^{3}$ Lauren Clayman ${ }^{4}$
}

\begin{abstract}
The life of Hall Effect thrusters are primarily limited by plasma erosion and thermal related failures. NASA Glenn Research Center (GRC) in cooperation with the Jet Propulsion Laboratory (JPL) have recently completed development of a Hall thruster with specific emphasis to mitigate these limitations. Extending the operational life of Hall thursters makes them more suitable for some of NASA's longer duration interplanetary missions.

This paper documents the thermal model development, refinement and correlation of results with thruster test data. Correlation was achieved by minimizing uncertainties in model input and recognizing the relevant parameters for effective model tuning. Throughout the thruster design phase the model was used to evaluate design options and systematically reduce component temperatures. Hall thrusters are inherently complex assemblies of high temperature components relying on internal conduction and external radiation for heat dispersion and rejection. System solutions are necessary in most cases to fully assess the benefits and/or consequences of any potential design change. Thermal model correlation is critical since thruster operational parameters can push some components/materials beyond their temperature limits.
\end{abstract}

This thruster incorporates a state-of-the-art magnetic shielding system to reduce plasma erosion and to a lesser extend power/heat deposition. Additionally a comprehensive thermal design strategy was employed to reduce temperatures of critical thruster components (primarily the magnet coils and the discharge channel). Long term wear testing is currently underway to assess the effectiveness of these systems and consequently thruster longevity.

\footnotetext{
${ }^{1}$ Senior Aerospace Engineer, Vantage Partners LLC, 3000 Aerospace Parkway, Brook Park, Ohio 44142 AIAA AIAA member.

${ }^{2}$ Senior Research Engineer, In Space Propulsion Systems, NASA Glenn Research Center, 21000 Brookpark Rd, Cleveland, Ohio 44135/MS 301:202, AIAA Associate Fellow.

3 Aerospace Engineer, Electric Propulsion Systems Branch, 21000 Brookpark Rd, Cleveland, Ohio 44135/MS 301:3, AIAA member.

${ }^{4}$ Aerospace Engineer, Thermal Systems Branch, 21000 Brookpark Rd, Cleveland, Ohio 44135/MS 86:350L, AIAA Non-member.
} 


\section{Nomenclature \& Acronyms}

$\begin{array}{ll}\alpha & \text { solar absorbtivity } \\ \boldsymbol{\varepsilon} & \text { emissivity or emittance } \\ \text { AU } & \text { Astronomical Unit } \\ \text { B-field } & \text { Magnetic field } \\ \text { BC } & \text { Boundary Condition } \\ \text { CAD } & \text { Computer Aided Design } \\ \text { CTE } & \text { Coefficient of Thermal Expansion } \\ \text { DC } & \text { Discharge Channel } \\ \text { GRC } & \text { Glenn Research Center } \\ \text { Gw2w } & \text { Thermal Conductance wire-to-wire } \\ \text { Hall2De } & \text { Hall thruster plasma modeling software } \\ \text { HERMES } & \text { Hall-Effect Rocket with MagnEtic Shielding } \\ \text { IPS } & \text { Ion Propulsion System } \\ \text { IR } & \text { InfraRed } \\ \text { Isp } & \text { Specific Impulse } \\ \text { ITAR } & \text { International Traffic in Arms Regulations } \\ \text { JPL } & \text { Jet Propulsion Laboratory } \\ \text { LEO } & \text { Low Earth Orbit } \\ \text { RADCAD } & \text { Radiation analysis software } \\ \text { R-C } & \text { Resistor-Capacitor } \\ \text { S/C } & \text { Space Craft } \\ \text { SEP } & \text { Solar Electric Propulsion } \\ \text { SOA } & \text { State Of the Art } \\ \text { STMD } & \text { Space Technology Mission Directorate } \\ \text { TC } & \text { ThermoCouple } \\ \text { TD } & \text { Thermal Desktop (analysis software) } \\ \text { TDM } & \text { Technology Demonstration Mission } \\ \text { TDU } & \text { Technology Demonstration Unit } \\ \text { TIM } & \text { Thermal Interface Material } \\ \text { USML } & \text { U.S. Munitions List } \\ \text { VF-5 } & \text { Vacuum Facility - 5 } \\ & \end{array}$




\section{Introduction}

Wasa Glenn Research Center (GRC) in cooperation with the Jet Propulsion Laboratory (JPL) have recently completed the design, development and comprehensive performance/thermal/wear testing of the Hall Effect Rocket with Magnetic Shielding (HERMeS) thruster under the Solar Electric Propulsion - Technology Demonstration Mission (SEP-TDM) project. This thruster was developed to support the high performance and extended life requirements of NASA's potential interplanetary missions such as Asteroid Redirect Robotic Mission (ARRM). NASA has invested much research in the development of high specific impulse (Isp) electric propulsion thrusters for space flight use [1]. The state-of-the-art systems implemented in the HERMeS design reduce plasma erosion and promotes lower operating temperatures. The benefits of such are expected to meet the lifetime requirements of ARRM, to be verified at the conclusion of long term wear testing.

Since these devices operate in the vacuum of space, heat rejection becomes a critical part of their design. Heat dissipation is largely restricted to passive modes of conduction and radiation as active cooling systems add complexity, expense, weight and probable reliability and safety concerns. Due to interactions with discharge plasma some Hall thruster components inherently operate at elevated temperatures $(>600 \mathrm{C})$. This hall thruster is constructed of multiple metals and ceramics which can induce large differential growth associated with the coefficient of thermal expansion (CTE) of each material. Heat generated by the internal components must be conducted to the exterior surfaces of the thruster for rejection via radiation. Nearly all of these conductive paths can have multiple bolted interfaces that must be designed to efficiently transfer heat and yet reduce thermal stresses particularly in the ceramic components.

A detailed thermal model of the thruster assembly is the only practical method to predict the operating temperatures of all components. Therefore a computational thermal model was developed to aid the design process of the components and interfaces throughout the thruster assembly. Model analyses can quickly quantify the thermal benefits associated with changes in component materials, contact surface areas, surface coatings and emissivities, bolt size/spacing/torques, thermal interface materials (TIM's), etc.

In an effort to best simulate in-space conditions, the laboratory testing of the HERMeS thruster was performed with minimal conductive heat sinks. The thruster must shed nearly all of its heat load via radiation, since the space craft (SC) typically cannot be used as a heat sink for such high power devices. Therefore the thermal model must also predict the radiative heat dissipation from the thruster to the ultimate sink being the vacuum tank or space. The thermal network of this thruster assembly and its environment has many paths, all of which influence each other. As a result the use of hand calculations to assess design changes can sometimes be woefully inadequate.

\section{Thermal Model Overview}

A computer model of the HERMeS Hall thruster was developed during the design phase to aid decisions about hardware features to improve the thruster's heat dissipation. The model was developed expanding on modeling techniques used on prior NASA/GRC laboratory Hall thrusters [2]. The model represents the physical hardware of the thruster, excluding the cathode as this was modeled separately. Its primary purpose is to predict component temperatures to ensure they remain within their maximum allowable temperature limits under all operating conditions. The model simulates the thermal performance of the thruster. The discharge plasma dynamics of the propellant has been modeled by NASA/JPL [3] with the resultant heat loads applied on the thruster's discharge channel (DC), anode and other non-shielded surfaces. The model accounts for all conductive and radiative exchange of thermal energy. All solutions are steady state representing peak operating temperatures of the thermal design.

The thermal model was used to guide the progressive design/development of the HERMeS thruster. In fact, following the initial thruster test sequence the model was put to task to assess the thermal benefits (and/or drawbacks) of multiple redesign options considered to reduce temperatures of critical components (primarily the inner coil, inner front pole and the DC). These included modifications to enhance contact conductance at bolted interfaces, component material selections, surface coatings/emissivities and TIM's. These analyses concluded with a 
set of design changes resulting in a predicted $133 \mathrm{C}$ reduction in inner coil temperature. Following these modifications, thruster testing showed a $145 \mathrm{C}$ reduction. At these lower operating temperatures the thruster design was deemed ready to complete the remaining thruster performance and wear tests.

\section{Thermal Model Description}

The thermal model of the HERMeS thruster was developed using a well proven commercial code for thermal analysis [4]. The origin of this code dates back to the Apollo program and has been widely accepted by NASA as their standard for thermal/contained fluid analysis. It generates finite difference and/or finite element meshes of R-C networks with solutions derived by matrix inversion techniques. The model defines numerous operating cases under vacuum tank and in-space operations. The various operational cases simulate the plasma and magnetic coil $\left(\mathrm{I}^{2} \mathrm{R}\right)$ heating. Thruster test results have confirmed the plasma heat loads are a function of thruster discharge power, discharge voltage and magnetic field strength. The plasma heat loads, derived from the Hall2De plasma model [3], were provided for two operating conditions; $9.4 \mathrm{~kW}$ at $300 \mathrm{~V}$ and $12.5 \mathrm{~kW} 600 \mathrm{~V}$. The ohmic heating of the magnet coils range with the desired magnetic field setting and are calculated in the thermal model by coil currents and electrical resistivity as a function of temperature.

For laboratory testing the model includes a medium fidelity representation of the vacuum facility \#5 (VF-5) tank including the HiVac cryo-panels to accurately model the thruster's thermal environment. Heating of the beam target (from the thruster plume) is not represented, as plume dispersion at the target size/distance are such that minimal heating occurs $(<3 \mathrm{C})$. The model currently predicts unpowered (dormant) thruster steady state temperatures to within $1 \mathrm{C}$ of the test data providing a high degree of confidence in the accuracy of the modeled tank environment. The in-space cases simulate deep space, low earth orbit (LEO) and solar inertial interplanetary environments of 0.8 and 1.9 AU per ARRM guidelines. Once correlated with laboratory (vacuum tank) test data, the thruster model can be integrated with models of prospective vehicles for verification of mission requirements simulating space flight operations.

The thermal model contains 9608 nodes over 19 component submodels as summarized in Table 1. A nodal plot of the thruster model is shown in Figure 1.

\section{Table 1 - Thermal Model Summary}

\begin{tabular}{|c|c|c|}
\hline Component & Submodel(s) & \# of Nodes \\
\hline Anode & Anode & 174 \\
\hline Backpole & Backpole & 936 \\
\hline Discharge Chamnel (DC) & Dischamber & 636 \\
\hline DC Mount Ring & DCRing & 1077 \\
\hline Thruster Mount & GimabalMnt & 252 \\
\hline Inner Coil Bobbin & Incoil ob & 258 \\
\hline Inner Magnet Coil & InMagCoil L1 to L12 & 2097 \\
\hline Mid-stem & InnerC ore & 702 \\
\hline Inner Front Pole & InnerF tPole & 153 \\
\hline Inner Magnet Shield & Inners hield & 540 \\
\hline Outer Coil Bobbin & OutCoilBob & 300 \\
\hline Outer Magnet Coil & OutMagCoil L1 to L6 & 540 \\
\hline Outer Magnet Shield & Outershield & 540 \\
\hline Outer Front Pole & OuffrtPole & 108 \\
\hline Outer Magnet Guide & Out upRing & 324 \\
\hline Radiator & Radiator & 360 \\
\hline Rear Cover & RearScreen & 1 \\
\hline Thruster Test $S$ tand & Thrust $S$ tand & 528 \\
\hline \multirow[t]{2}{*}{ Vacuvem Tank } & VacTank & 82 \\
\hline & Total $=$ & 9608 \\
\hline
\end{tabular}


Since the thruster operates at elevated temperatures the material thermal properties can be significantly different than those at ambient temperature. Therefore the thermal conductivity, specific heat and surface emissivity of nearly all materials and coatings were obtained for (or near) the component's maximum operating temperature if a temperature dependent curve could not be found. The model input or parameters that dominate the thruster temperatures are; surface emittance, interface contact conductances and plasma heat loads. Each of these parameters presents a challenge to define accurate modeling input. The model also includes a 2 meter diameter adiabatic disk (SCblockage submodel), centered behind the thruster to represent shadowing of environmental fluxes (and space view factors) by the SC vehicle for preliminary in-space analyses.

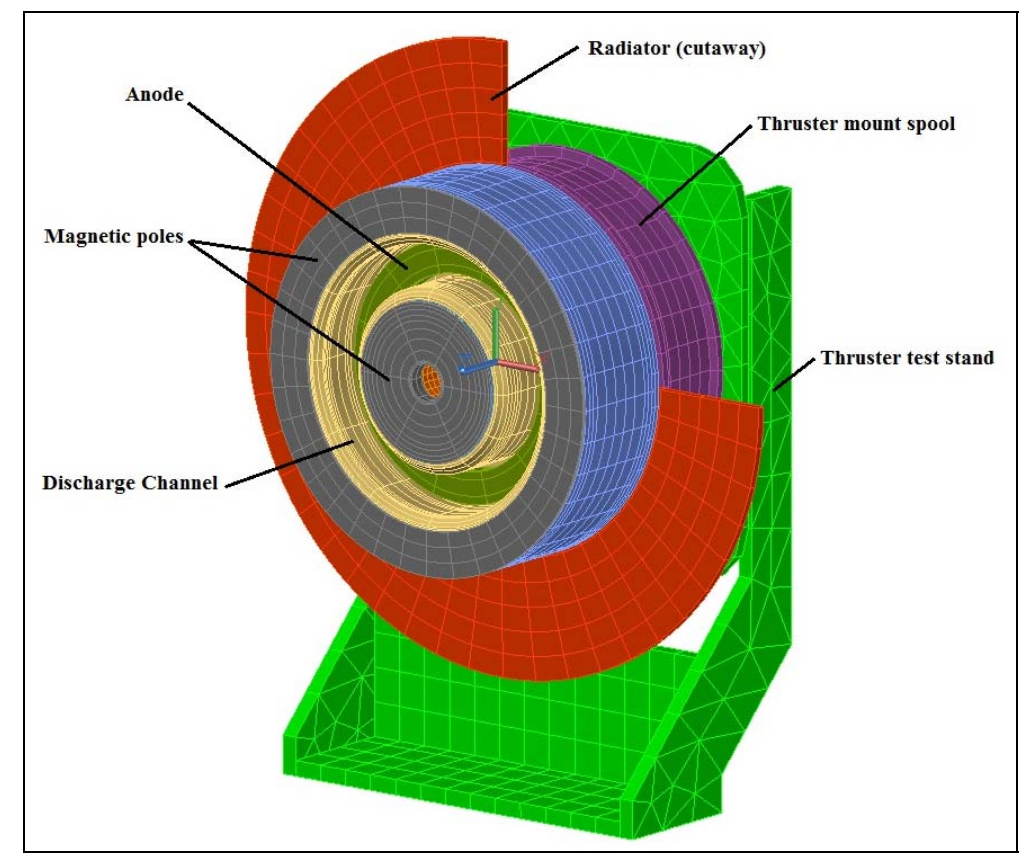

\section{Figure 1 - HERMeS Thruster Thermal Model}

Of all the components that comprise the thruster assembly the inner electromagnet coil is considered to be most susceptible to thermal failure for the following reasons. First, the electrical insulation on the coil windings has the lowest material temperature limit. Second, the inner coil is surrounded by the DC where propellant ionization occurs making it one of the hottest components in the thruster. Therefore a more rigorous effort was applied to develop high fidelity submodels of the inner and outer magnet coils. Both coils were custom wound to achieve the maximum B-field per HERMeS thruster design specifications. During the winding process the coils were potted with a ceramic material to increase thermal conductance between the windings and thereby reduce thermal gradients (hot spots) within the coils. Ideally this potting creates a coil assembly free of voids by filling the gaps between the windings. However in practice, the ceramic potting compound suffers from cracks due to the large startup gradients (ambient to operating $\Delta \mathrm{T}$ ) and the large difference in CTE of the constituent materials (ceramic and copper). Further development is expected to mitigate this issue in the flight design.

The radial and axial thermal conductance through the potted coil assemblies were calculated using discreet integration across the symmetrical $x$-section of the coil windings as shown in Figure 2 (left illustration). The conduction areas of the 3 constitute materials (copper, insulation \& potting) were integrated over a $90^{\circ}$ segment of the wire $\mathrm{x}$-section also shown in Figure 2 (right illustration). As heat conducts from the center of one wire to the OD of the insulation the material of the conduction path changes from a high percentage of copper and some insulation at $\theta=0$ to $100 \%$ potting at $\theta=90^{\circ}$. An example of the tabulation of the integrated thermal conductance for one coil layer is presented in Table 2. This yields wire-to-wire conductance $(\mathrm{Gw} 2 \mathrm{w})$ which can be applied in the radial and axial coordinates. The radial conductance is simply (Gw2w) (\# of turns) for each layer. This is applied as contact conductance since as modeled each layer contains only one node in the radial direction. 


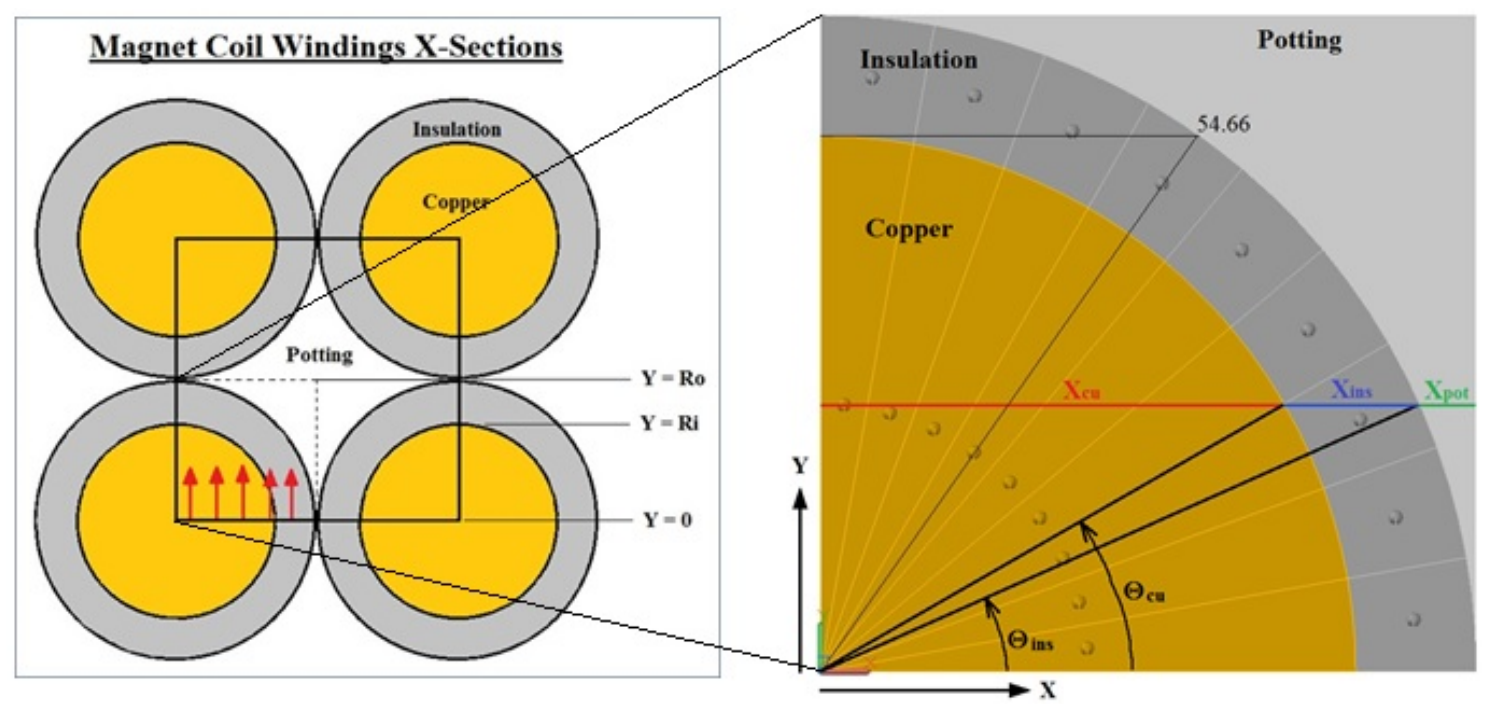

Figure 2 - Coil Windings X-Section \& Conductance Integration Diagram

\section{Table 2 - Integrated Thermal Conductance of Magnet Coil Windings}

\begin{tabular}{|c|c|c|c|c|c|c|c|c|c|c|c|c|c|c|c|}
\hline $\begin{array}{c}\text { Step } \\
\#\end{array}$ & & $\theta \mathrm{cu}$ & $\mathrm{Y}$ & $\Delta \mathrm{Y}$ & $\mathrm{Xcu}$ & $\theta_{\text {ins }}$ & $\mathrm{X}_{\text {ins }}$ & Xpot & Acu & Ains & Apot & $\begin{array}{l}\mathrm{Rcu} \\
(\mathrm{C} / \mathrm{W})\end{array}$ & $\begin{array}{l}\text { Rins } \\
(\mathrm{C} / \mathrm{w})\end{array}$ & $\begin{array}{l}\text { Rpot } \\
\text { (C/w) }\end{array}$ & \\
\hline 0 & & 0 & 0 & 0 & 0.02855 & 0 & 0.00645 & 0 & 0.4296775 & 0.0970725 & 0 & $1.13 \mathrm{E}-03$ & 51.07179631 & $\infty$ & \\
\hline 1 & & 10 & 0.004958 & 0.004958 & 0.0281163 & 8.14318 & 0.006531 & 0.000353 & 0.4231497 & 0.09828915 & 0.0053111 & $1.12 \mathrm{E}-03$ & 48.90702522 & 13.7133873 & \\
\hline 2 & & 20 & 0.009765 & 0.004807 & 0.0268282 & 16.2 & 0.006782 & 0.00139 & 0.4037647 & 0.10207001 & 0.0209153 & $1.10 \mathrm{E}-03$ & 44.18862535 & 3.26738136 & \\
\hline 3 & & 30 & 0.014275 & 0.00451 & 0.024725 & 24.0703 & 0.007232 & 0.003043 & 0.3721114 & 0.10883528 & 0.0458034 & $1.08 \mathrm{E}-03$ & 37.45652756 & 1.34851573 & \\
\hline 4 & & 40 & 0.018352 & 0.004077 & 0.0218705 & 31.6232 & 0.007932 & 0.005197 & 0.3291516 & 0.11938333 & 0.0782151 & $1.05 \mathrm{E}-03$ & 29.47634643 & 0.68168385 & \\
\hline 5 & & 50 & 0.021871 & 0.003519 & 0.0183515 & 38.6729 & 0.008974 & 0.007675 & 0.2761907 & 0.13505632 & 0.115503 & $1.02 \mathrm{E}-03$ & 21.135286 & 0.37444317 & \\
\hline 6 & & 60 & 0.024725 & 0.002854 & 0.0142749 & 44.9451 & 0.010497 & 0.010228 & 0.2148378 & 0.15798666 & 0.1539255 & $9.62 \mathrm{E}-04$ & 13.31246582 & 0.20702577 & \\
\hline 7 & & 70 & 0.026828 & 0.002103 & 0.0097646 & 50.0424 & 0.012713 & 0.012522 & 0.1469572 & 0.19133147 & 0.1884613 & $8.61 \mathrm{E}-04$ & 6.731905167 & 0.10355194 & \\
\hline 8 & $\mathrm{Ri}$ & 80 & 0.028116 & 0.001288 & 0.0049576 & 53.4484 & 0.015886 & 0.014156 & 0.0746113 & 0.23909181 & 0.2130469 & $5.71 \mathrm{E}-04$ & 1.814041525 & 0.03084557 & \\
\hline 9 & & 90 & 0.02855 & 0.000434 & $-1.05 \mathrm{E}-07$ & 54.6579 & 0.020246 & 0.014754 & $-1.58 \mathrm{E}-06$ & 0.30470276 & 0.2220488 & $\infty$ & 5.77917969 & 0.1201573 & \\
\hline 10 & & & 0.030311 & 0.001761 & 0 & 60 & 0.0175 & 0.0175 & 0 & 0.26337388 & 0.2633761 & $\infty$ & 9.789672051 & 0.14832711 & \\
\hline 11 & & & 0.032889 & 0.002578 & 0 & 70 & 0.011971 & 0.023029 & 0 & 0.1801577 & 0.3465923 & $\infty$ & 8.764628458 & 0.06902771 & \\
\hline 12 & & & 0.034468 & 0.001579 & 0 & 80 & 0.006078 & 0.028922 & 0 & 0.09146748 & 0.4352825 & $\infty$ & 5.813090927 & 0.01850797 & \\
\hline \multirow[t]{16}{*}{13} & Ro & & 0.035 & 0.000532 & 0 & 90 & $-1.3 \mathrm{E}-07$ & 0.035 & 0 & $-1.935 E-06$ & 0.5267519 & $\infty$ & $\infty$ & 0.01529409 & \\
\hline & & \multicolumn{3}{|c|}{ Copper radius; $\mathrm{Rcu}=$} & & in & & & \multicolumn{3}{|c|}{ Integrated $\mathrm{Ri}$ values $=>$} & $8.882 \mathrm{E}-03$ & 254.0940194 & $1.973 \mathrm{E}+01$ & \\
\hline & & \multicolumn{4}{|c|}{ Radius of Insulation; Rins $=$} & 0.035 & in & & \multicolumn{2}{|c|}{ Parallel Resistors } & & & & & \\
\hline & & \multicolumn{4}{|c|}{ Length of wire 1 turn coil layer; } & 15.05 & in & & \multicolumn{4}{|c|}{$\mathrm{Gi}$ Total $=1 / \mathrm{Rcu}+1 / \mathrm{Rins}+1 / \mathrm{Rpot}=$} & $1.126 \mathrm{E}+02$ & $\mathrm{~W} / \mathrm{C}$ & \\
\hline & & \multicolumn{4}{|c|}{ Thermal Cond of Copper; Kcu } & 10.18 & $\mathrm{~W} /$ in- $\mathrm{C}$ & & & & & & & & \\
\hline & & \multicolumn{5}{|c|}{ Thermal Cond of Insulation; Kcl 0.001} & $\mathrm{~W} / \mathrm{in}-\mathrm{C}$ & & \multicolumn{3}{|c|}{ Integrated Ro values $\Rightarrow>$} & $\infty$ & $3.015 E+01$ & 3.713E-01 & \\
\hline & & \multicolumn{5}{|c|}{ Thermal Cond of Potting; $\mathrm{Kcu}=0.066$} & $\mathrm{~W} / \mathrm{in}-\mathrm{C}$ & & \multicolumn{2}{|c|}{ Parallel Resistors } & & & & & \\
\hline & & & & & & & & & Go Total & \multicolumn{2}{|c|}{$1 /$ Rins $+1 /$ Rpot $=$} & $2.726 \mathrm{E}+00$ & $\mathrm{~W} / \mathrm{C}$ & & \\
\hline & & & & & & & & & & & & & & & \\
\hline & & & & & & & & & \multicolumn{3}{|c|}{ Series Conductors Gtotal $=$} & \multicolumn{2}{|c|}{$1 /[1 / \mathrm{Gi}+1 / \mathrm{Go}]=$} & $2.662 \mathrm{E}+00$ & $\mathrm{~W} / \mathrm{C}$ \\
\hline & & & & & & & & & \multicolumn{5}{|c|}{ This is conductance thru $1 / 2$ wire thickness. } & & \\
\hline & & & & & & & & & & & & & & & \\
\hline & & & & & \multicolumn{8}{|c|}{ The conductance thru width of one wire is (parallel conductors); $2 \times \mathrm{Gt}=$} & $=5.324 \mathrm{E}+00$ & $\mathrm{~W} / \mathrm{C}$ & \\
\hline & & & & & & & & & & & & & & & \\
\hline & & & & & \multicolumn{9}{|c|}{ The conductance thru the depth of one wire or center-to-center is (series conductors); } & & \\
\hline & & & & & \multicolumn{5}{|c|}{$\mathrm{Gw} 2 \mathrm{w}=1 /[1 / \mathrm{Gw}+1 / \mathrm{Gw}]=$} & 2.662 & $\mathrm{~W} / \mathrm{C}$ & & & & \\
\hline
\end{tabular}

For the axial direction the thermal conductivity is calculated for each layer as Kax varies with the number of turns for each layer.

Conduction area and material $\mathrm{x}$-sections do not change around the circumference of the coil. This allows the use of a simple area weighted effective thermal conductivity for the azimuthal direction. Since the thermal conductivity of the coil assembly varies with the coordinate axes an anisotropic definition is required for each layer of the coil windings. 
The electrical resistance of the copper windings is temperature dependent in accordance with the following expression;

$$
\mathrm{R}=\operatorname{Ro}[1+\mathrm{a}(\mathrm{T}-\mathrm{To})]
$$

where Ro is resistance at specified temp To, $\mathrm{a}=$ temp coefficient $=0.00386$

Therefore the electrical resistance is calculated at the winding temperature to determine the internal heating $\left(I^{2} R\right)$. This was done for each layer of the coil windings. Note that the elevated temperature of these coils more than doubles its electrical resistance. Each row of the windings was modeled as a separate layer. Each layer was further discretized into one-half the number of turns and 8 segments in circumference.

\section{Heat Sources and Sinks}

For lab operations there are three sources of heat load on the thruster: plasma heating, ohmic heating in the magnet coils, and cathode heating. The primary source of heat in the thruster is from the ionized propellant, termed plasma power deposition. The xenon plasma deposits heat via particle bombardment with the bounding surfaces of the anode, the DC and the inner front pole. The outer front pole is neglected due to very low plasma density in this region. These heat loads are associated with the ionization, containment and acceleration of the propellant. These loads are calculated by NASA/JPL using the Hall2De [3] computational model. The particle physics associated with these calculations is well beyond the scope of this report (see reference 3 for details). These plasma heat loads are calculated for maximum power $12.5 \mathrm{~kW}$ (thermal worst case; $600 \mathrm{~V}$ discharge voltage) and applied to the surfaces of the thermal model. Heat flux along the walls of the DC for the original baseline case are plotted in Figure 3. As described later in section VIII, scale factors were applied to these plasma heat loads to accurately match the test temperatures.

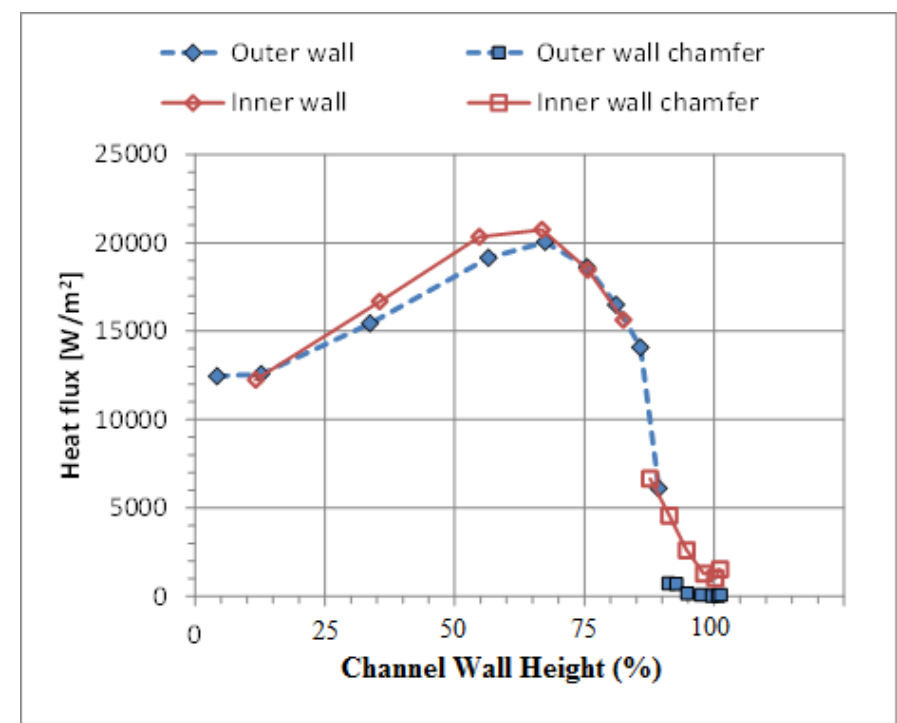

Figure 3 - Plasma Heat Flux on Discharge Channel (Typ)

The HERMeS Hall thruster is equipped with magnetic shielding. This provides a level of protection against the eroding effects of the plasma. The magnetic field is generated with two electromagnetic coils (inner and outer with respect to the DC). The B-field is contoured by balanced coil currents yielding field lines that oppose particle impingement with the DC surfaces. This significantly reduces erosion of the DC.

Resistive heating $\left(I^{2} R\right)$ of the coil windings is calculated in the thermal model as a function of coil current and temperature. These heat loads are applied to coil windings layer-by-layer in the model. The heat generated by the magnet coils at max thruster power, max discharge voltage and optimized B-field $(12.5 \mathrm{~kW} / 600 \mathrm{~V})$ are calculated as 
$44 \mathrm{~W}$ and $48 \mathrm{~W}$ for the inner and outer coils respectively, based on test coil currents with resistance calculated at the operating temperatures.

The final source of heating is the cathode. The cathode is located on the central axis of the thruster. Mounted to the backpole, it protrudes through the center hole in the midstem. Separate detailed thermal models of the cathode(s) were developed as shown in Figure 4 with the resultant radiated heat ( $41 \mathrm{~W}$ for the $\mathrm{BaO}$ cathode) applied along the inner diameter of the mid-stem in the thruster model.

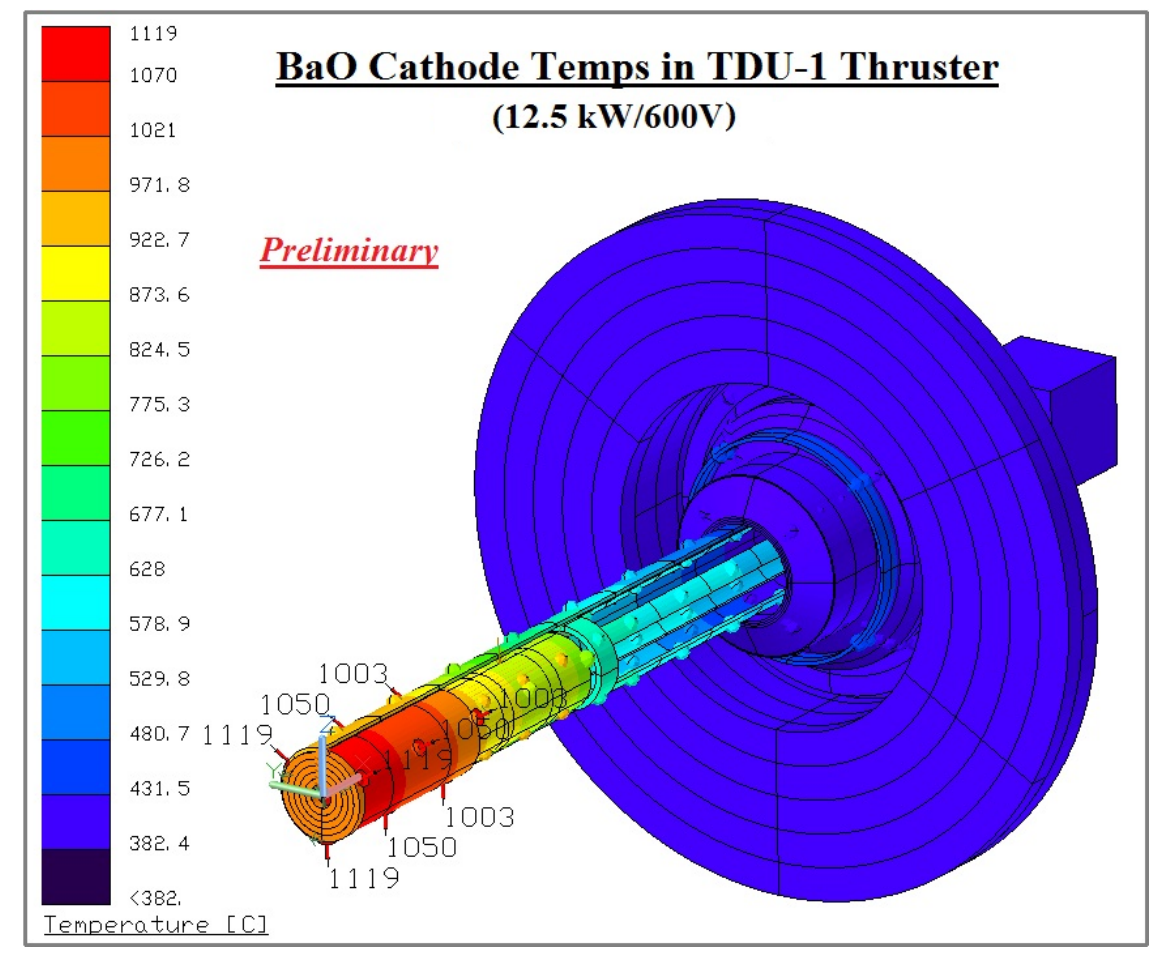

Figure 4- Cathode Thermal Model Results for TDU-1 Operations

A summary of the total thruster heat loads are listed in Table 3. A discussion of the scale factors and how they were used in model correlation is presented in section VIII.

Table 3 - Summary of Thruster Heat Loads

\begin{tabular}{|l|c|c|c|c|}
\hline Component & $\begin{array}{c}\text { Predicted Heat } \\
\text { (W) }\end{array}$ & DC_Factort & Pole_Factort & $\begin{array}{c}\text { Total Heat Loads } \\
\text { (W) }\end{array}$ \\
\hline Inner Magnet Coil & 44.1 & - & - & 44.1 \\
\hline Outer Magnet Coil & 48.1 & - & - & 48.1 \\
\hline Anode & 496 & 0.52 & - & 257.9 \\
\hline Cathode & 41 & - & - & 41.0 \\
\hline DC Walls & 1056 & 0.52 & - & 549.1 \\
\hline Inner Front Pole & 181 & - & 0.23 & 41.6 \\
\hline \multicolumn{5}{|r|}{} \\
\hline \multicolumn{2}{|l|}{ † DC_Factor and Pole_Factor determined by iterative analysis to match test temps. } \\
\hline
\end{tabular}




\section{Thermal Boundary Conditions}

The thruster is mounted to a test stand as shown in Figure 5 for all vacuum tank testing. The base of the stand is mounted to the thrust measurement device. This mount provides electrical and some limited thermal isolation. The stand base temperature was recorded $(42 \mathrm{C}$ ) and used as the conductive Boundary Condition (BC) in the thermal model for VF-5 vacuum tank operations. The model currently shows $60 \mathrm{~W}$ or $\sim 6 \%$ of thruster's total heat load is conducted into this structure at maximum thruster temperatures.

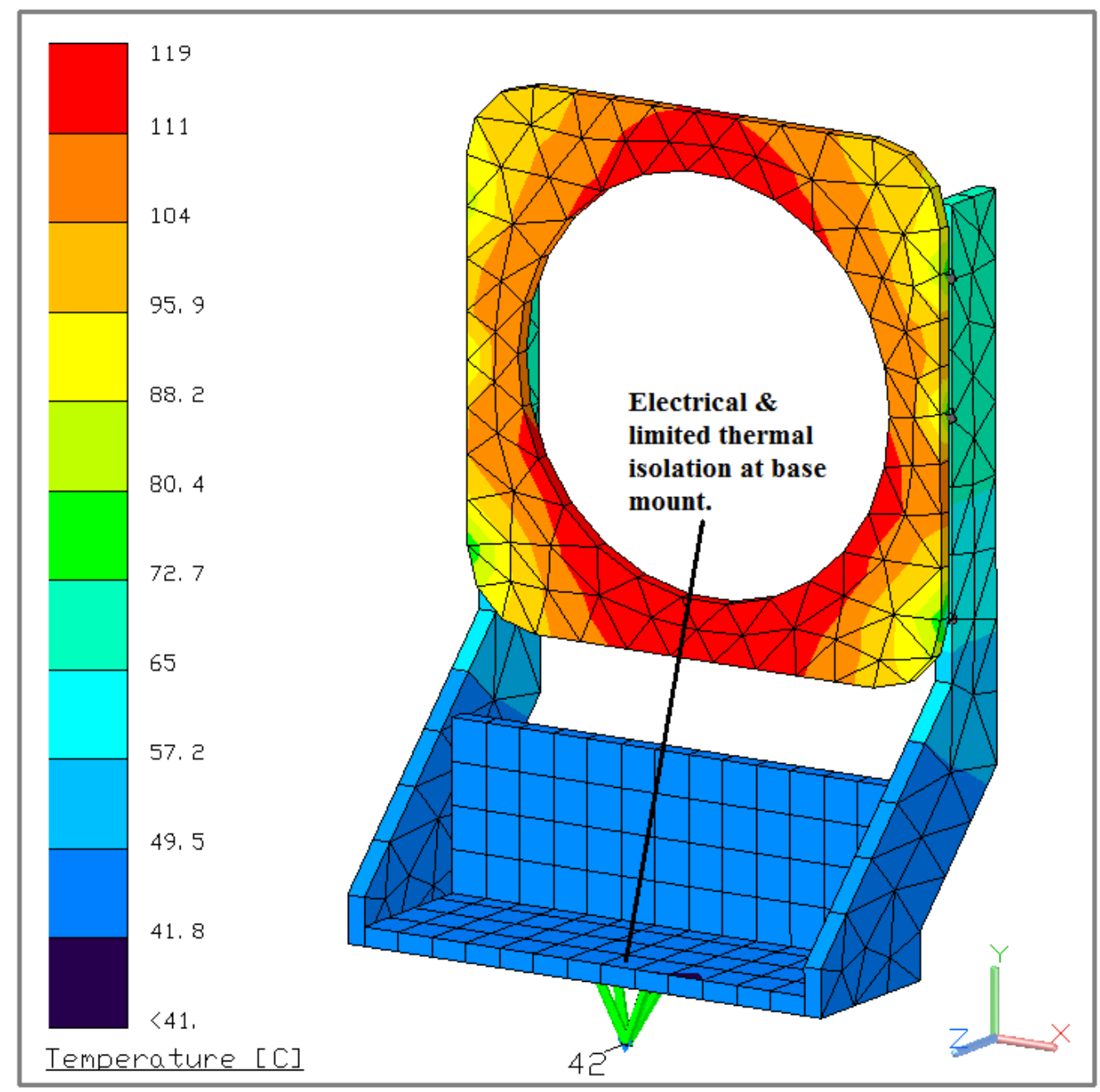

Figure 5 - Thruster Test Stand Temperatures

The final piece of the thermal model is the VF-5 vacuum tank. This submodel as shown in Figure 6 was developed to more accurately define the thermal environment of the thruster. The thruster is located at the coordinate origin in the figure. All cryo-panel/baffles are fixed temperature boundary nodes (dark blue surfaces) consistent with their cryo-fluids. Exterior convection to ambient temperature $(20 \mathrm{C})$ is adjusted to achieve the dormant thruster temperature of $-27 \mathrm{C}$ matching test data. Therefore environmental heat loads (negative) are applied in situ from the radiative interactions of the thruster within the tank. This is considerably more accurate than a single sink temperature (commonly used) as it accounts for the proximity of the cryo-surfaces and the total summation of view factors for all thruster and tank surfaces. 


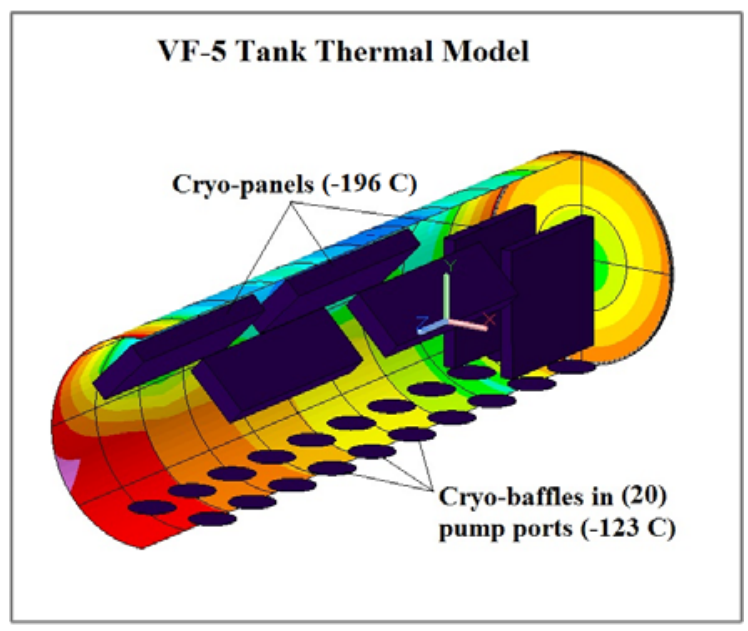

\section{Figure 6 - VF-5 Vacuum Tank (Cut-Away)}

In addition to the test environment, the model contains several in-space orbital and AU interplanetary environments for mission analyses. These results are presented in section IX.

\section{Thruster Test Results}

Extensive testing has been performed at NASA/GRC on multiple design configurations and subsequent modifications of the HERMES thruster (original design, thermal shunt and radiator). For simplicity only the results of the final configuration (radiator) are presented here. Just to note, the test records for all thruster configurations have been post processed and recorded in HERMeS project archives. Ultimately these other configurations demonstrated the need for additional conductive cooling of the DC to maintain component temperatures within their desired limits. However for HERMeS this cooling path was intentionally restricted in the initial design to minimize heat transfer to the SC vehicle. However, the resultant higher DC temperatures $(\sim 700 \mathrm{C})$ promoted high frequency oscillations (pulsing) in the thruster discharge that were deemed unacceptable. Fortunately the requirement to minimize heat flow to the vehicle can be met with other thermal methods such as thermal isolating mounts and MLI. The radiator configuration as shown in Figure 7 produced the lowest component temperatures at maximum operating conditions.

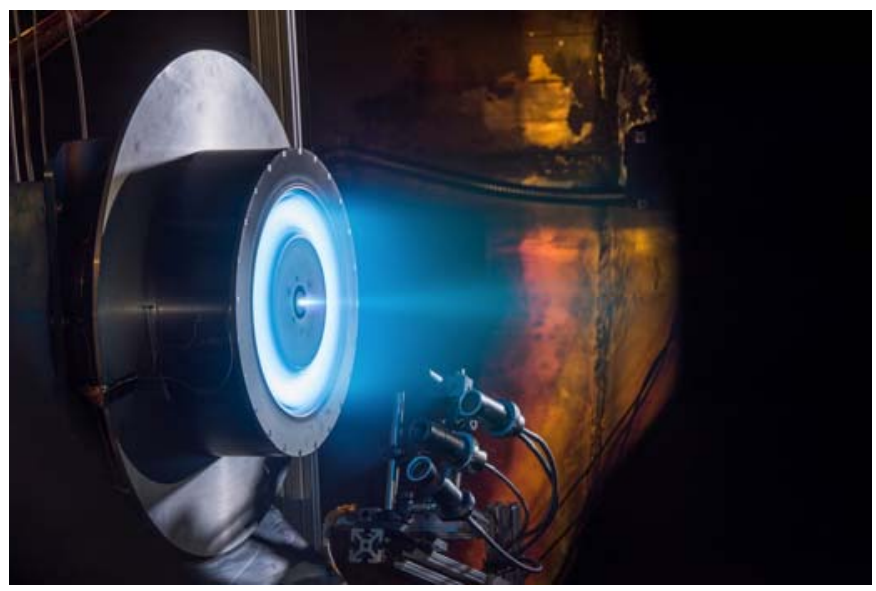

Figure 7 - Operation of HERMES TDU-1 at NASA/GRC

American Institute of Aeronautics and Astronautics 
Thruster temperatures were found to be a function of three operational parameters; discharge power, discharge voltage and B-field intensity. Maximum values of all three produced worst case hot operating conditions. Steady state temperatures of all components except the anode and cathode were recorded with thermocouples (TC's). Multiple TC's were placed on thermally critical components and/or components with large gradients. Most components displayed thermal gradients associated with conduction through the thruster assembly. TC's were located near the maximum temperature regions wherever practical. Steady state component temperatures from the TDU-1 wear tests are presented in Table 4. The average temperature of components with multiple TC's is adjacent to each column of test temperatures (discharge channel - gold, outer coil - green, inner coil - red, radiator - blue, DC mount ring - gray, etc.). Evaluation of the thruster performance data will determine the optimal B-fields for all operating points within the thruster throttle table.

\section{Table 4 - HERMeS Thruster Max Operating Temperatures (4/29/16 Test@12.5 kW/600V)}

\begin{tabular}{|c|c|c|c|c|}
\hline Component & $\begin{array}{c}\text { Data } \\
\text { File } \\
\text { Column }\end{array}$ & $\begin{array}{c}12.5 \mathrm{~kW} \\
600 \mathrm{~V} \\
\text { Test T emps } \\
\text { (C) }\end{array}$ & $\begin{array}{l}\text { Avg } \\
\text { Test } \\
\text { Temps } \\
\text { (C) }\end{array}$ & $\begin{array}{l}\text { Thermal } \\
\text { M argin } \\
\text { (C) }\end{array}$ \\
\hline DCouterwall Dwnstrm 3 Oc & BI & 404 & & \\
\hline DCouterwall Upstm $30 c$ & $\mathrm{Cl}$ & 343 & & \\
\hline DCinner wall Upstm $30 c$ & BJ & 341 & & \\
\hline DCinner wall Dwnstm $30 \mathrm{c}$ & $\mathrm{CH}$ & 364 & 363 & 296 \\
\hline DCBase 60clock & BK & 328 & & \\
\hline DCBase 12 Oclock & CK & 357 & 343 & 343 \\
\hline Outer Coil - Dwnstmm & $\mathrm{BH}$ & 271 & & \\
\hline Outer Coil - Upstrm & $C A$ & 272 & 272 & 253 \\
\hline Inner Coil - Upstrm & $\mathrm{BX}$ & 393 & & \\
\hline Inner Coil - Dwnstmm & CE & 380 & 387 & 132 \\
\hline DCMount Ring OD & $\mathrm{BL}$ & 308 & & \\
\hline DCMount Ring-ID & $\mathrm{CJ}$ & 319 & 314 & 181 \\
\hline Radiator OD $12 \mathrm{Oc}$ & $\mathrm{BO}$ & 8 & & \\
\hline Radiator $\mathrm{OD} 6 \mathrm{Oc}$ & $\mathrm{BP}$ & 178 & & \\
\hline Radiator ID & $\mathrm{CB}$ & 260 & 219 & 140 \\
\hline Back Pole Near OD & $B Z$ & 267 & & \\
\hline Backpole Near DC & $\mathrm{BR}$ & 278 & & \\
\hline Backpole Near ID & $\propto$ & 299 & 281 & 151 \\
\hline Spool Mount Front Flange & $B Q$ & 186 & & \\
\hline Spool Mount Rear Flange & $\mathrm{BN}$ & 106 & 146 & 164 \\
\hline Inner Front Pole $60 \mathrm{c}$ & $\mathrm{BU}$ & 309 & & \\
\hline Inner Front Pole $12 \mathrm{Oc}$ & $\infty$ & 306 & 308 & 191 \\
\hline Outer Screen & $B F$ & 285 & & 65 \\
\hline Inner Screen & $C D$ & 322 & & 228 \\
\hline Outer Front Pole-Inside & BG & 216 & & 134 \\
\hline Outer Guide - Middle & $\mathrm{BM}$ & 221 & & 129 \\
\hline Thrust Stand Base & $B V$ & 42 & & - \\
\hline Thrust Stand Arm & BY & 73 & & - \\
\hline Midstem & BS & 323 & & 202 \\
\hline Back Cover Plate & BT & 113 & & - \\
\hline Inner Magnet Ourrent (A) & $\mathrm{v}$ & 3.38 & & \\
\hline Outer Magnet Current(A) & $\mathrm{N}$ & 2.82 & & \\
\hline Values in red are suspect. & & & & \\
\hline
\end{tabular}


At these elevated temperatures some TC's produced anomalous or suspect readings (red). Subsequent inspection confirmed the TC at 12 Oclock on the radiator had lost contact. The current design carries large thermal margins ranging from 65 to $343 \mathrm{C}$ for all components.

The DC is subject to the highest temperatures. Six TC's were located on the DC (non-plasma sides) in an attempt to better define the distribution of plasma heating along the walls. The TC's were distributed to measure axial gradients along the walls as well as the interface $\Delta \mathrm{T}$ at the $\mathrm{DC}$ base mount. The error band on all TC's readings is $+/-5 \mathrm{C}$ at $500 \mathrm{C}$.

Initial development tests were performed at discharge voltages up to $800 \mathrm{~V}$ with the thruster meeting the design goals for Isp, efficiency, maximum thrust and component operating temperatures. However data from these initial tests have also shown the thruster meets all performance criteria at $600 \mathrm{~V}$. The reduced discharge voltage also lowered operating temperatures and suppressed some high frequency oscillations in the thruster discharge current.

\section{Model Correlation Parameters}

Making systematic adjustments to a computational model to match test results is referred to as model correlation. Test data comprised of component temperatures and magnet coil currents were used to correlate the thruster thermal model at the worst case (i.e., hottest) operating conditions $(12.5 \mathrm{~kW}, 600 \mathrm{~V})$. Model correlation or 'tuning' is an iterative process of parametric adjustments that ideally culminates with a good comparison of test versus model temperatures for all components. The thermal input parameters used to tune the model were: interface contact conductance, surface emissivities and plasma heat loads. Each of these parameters has varying degrees of uncertainty. In general, the surfaces emissivities and thruster heat loads dominate the temperatures of the exterior radiating surfaces and the interface conductance values control the temperature of the thruster's internal components. These three parameters control the temperature profile (i.e., gradients) within the thruster assembly. Although it should be noted that any one change such as conductance at one interface or emittance of one surface changes the heat flow through that path indirectly affecting the heat flow of other paths and the corresponding component temperatures. Thus the tuning process can be highly iterative attempting to achieve a balanced temperature profile in good agreement with test results.

Model correlation was achieved with data from the thruster configuration/operations during the wear tests (Table 4). The correlated model can then be used to thermally assess vehicle integration strategies/requirements and inspace mission scenarios by changing the environmental boundary conditions.

During model construction many input parameters are calculated, estimated or even assumed, if definitive information is not available. As noted earlier the key tuning parameters in this thermal model are; interface contact conductance, surface emittance of the various materials and plasma heat loads. Many factors influence these parameters that may be unknown or poorly defined such as, surface finish, flatness, hardness, effective contact areas, thermal distortion, heat loads, efficiencies, temperature dependence of material properties, particle physics, etc. Most parameters have nominal or expected values/ranges based on theoretical solutions or empirical data, with some more accurate than others. For simple applications with only a few input parameters, biased analyses can be performed using best and worst case values to bound the range of expected results (frequently called sensitivity studies). However for situations when many parameters are needed (for instance contact conductance at each interface in the entire thruster assembly, or emissivities of all/multiple exterior surfaces) the results of these sensitivity studies are often widely diverging. Such results provide little benefit in assessing the thermal performance of the design.

From the preceding discussion on uncertainties in modeling input parameters we must conclude some inaccuracies exist in any uncorrelated model. Well-conceived test measurements usually provide the best input. Such measurements were used to determine the surface emissivities of nearly all of the thruster materials thereby minimizing the source of error from this input. The emissivities of all clean surfaces/coatings were measured over the infrared range of 2 to $25 \mu \mathrm{m}$ at ambient temperature and mathematically projected ${ }^{\dagger}$ to temperatures up to $1300 \mathrm{~K}$ as shown in Figure 8. 
${ }^{\dagger}$ Derivation of temperature dependent emissivity provided in Appendix A.

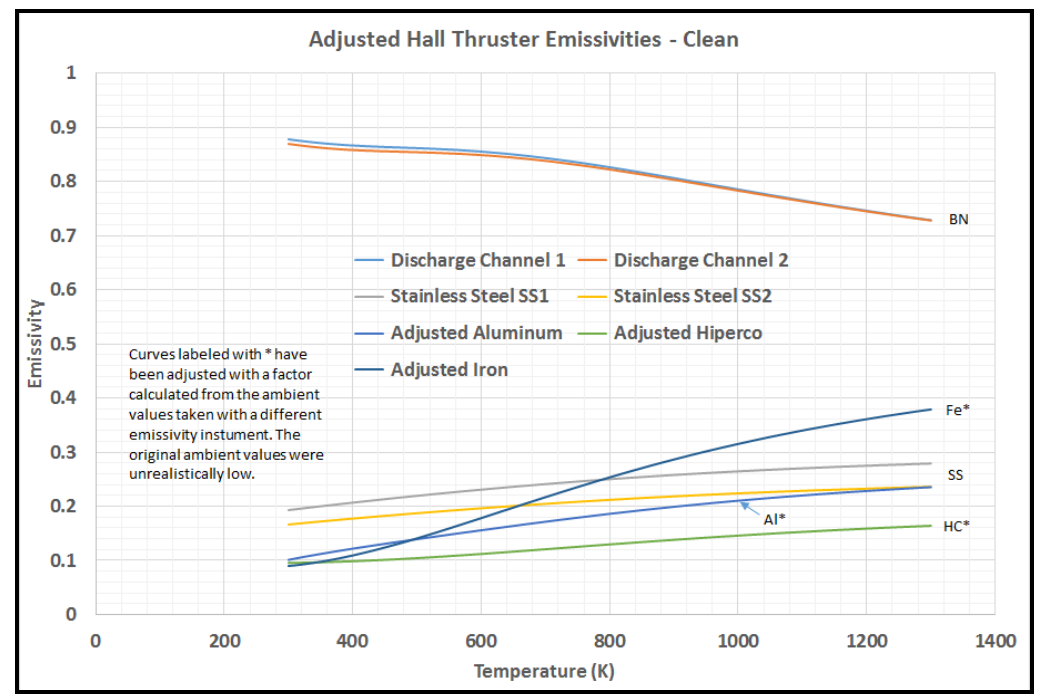

\section{Figure 8 - Emissivities of Thruster Materials/Surfaces}

During thruster testing a graphite target and shielding are used to protect the vacuum tank walls from the eroding effects of the thruster beam (exhaust plume). Unfortunately the thruster plume sputters these graphite surfaces resulting in carbon (graphite) deposition on thruster surfaces after only a short period of operation ( $\sim$ weeks). This deposition changes the emissivities of surfaces. The deposition rate and/or film thickness varies with surface orientation and time. Thruster surfaces were inspected between test series and some remain relatively clean, others developed a dark grey coating of carbon. Surfaces normal to the thruster axis facing downstream receive the heaviest depositions (such as the poles). Therefore emissivity measurements were taken of some 'dirty' thruster surfaces as shown in Figure 9. In general the graphite deposition increases the low emittance of clean metals resulting in slightly cooler thruster temperatures. For thermal model correlation some degree of discretion was applied to estimate the emissivity of dirty-to-clean surfaces. Thus, to a much lesser extent the emissivity of some external thruster surfaces were used as tunable parameters for model correlation.

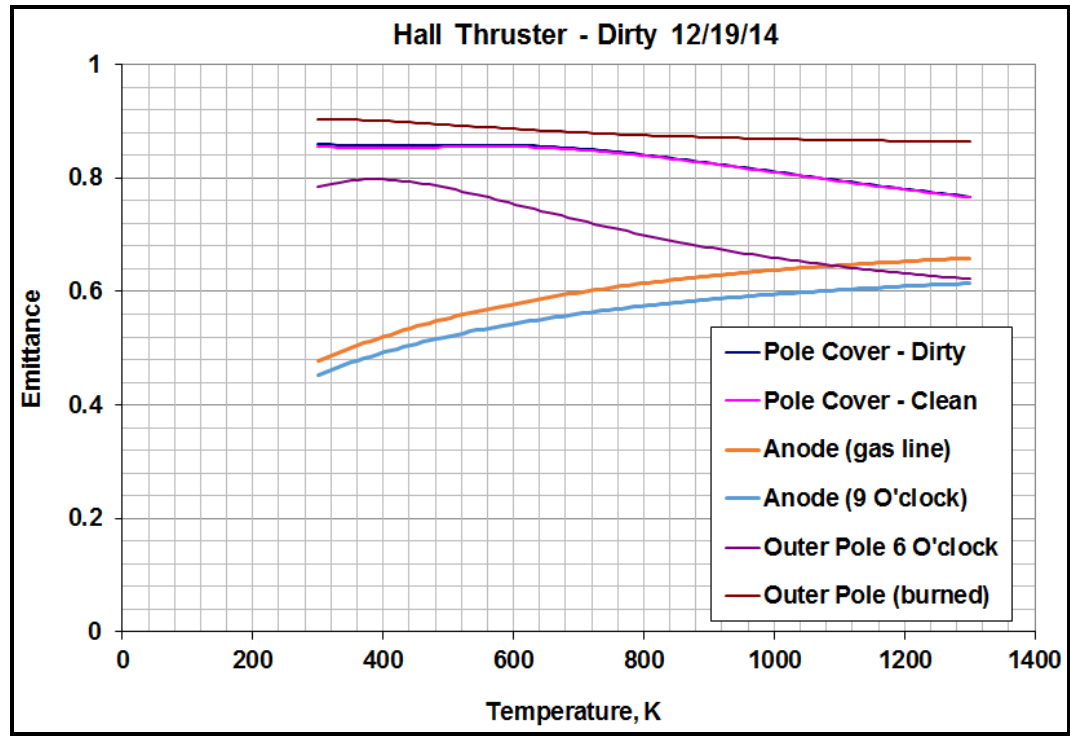

\section{Figure 9 - Emissivities of Surfaces with Graphite Depositions}

American Institute of Aeronautics and Astronautics 
After many days of testing the black oxide coating on the thruster exterior seemed to deteriorate. This high emissivity coating was an important feature in the radiative design for heat dissipation. Some of these surfaces developed a deep blue semi-gloss 'gun metal' appearance (even a rainbow of color at several locations). It was apparent the surface emissivity was degraded (i.e., semi-shiny appearance). The emissivities of these degraded surfaces could not be measured with the instruments at GRC due to their curved geometries. Therefore these 'key' values also became tunable parameters for model correlation.

The surface emittance values used in the correlated model (mainly measured values) are listed in Table 5.

\section{Table 5 - Surface Emittance}

\begin{tabular}{|l|c|c|l|}
\hline Component & Emittance & Temp (C) & Comments \\
\hline Discharge Channel & 0.8 & 400 & Carbon deposited \\
\hline Anode & 0.24 & 400 & Carbon deposited \\
\hline Pole Covers & 0.77 & 300 & \\
\hline Outer Guide & 0.5 & 250 & Deteriorated \\
\hline Radiator & 0.75 & 200 & Carbon deposited \\
\hline Spool Mount & 0.5 & 150 & Deteriorated \\
\hline Mount Plate & 0.75 & 100 & Carbon deposited \\
\hline Thruster Stand & 0.75 & 50 & Partial carbon deposited \\
\hline Backpole & 0.2 & 300 & Dirty \\
\hline Rear Cover & 0.75 & 100 & Clean \\
\hline Coil Windings & 0.11 & 400 & Sheet metal wrap \\
\hline Inner Coil Bobbin & 0.3 & 400 & \\
\hline Outer Coil Bobbin & 0.1 & 300 & \\
\hline Magnet Shields & 0.13 & 300 & \\
\hline Midstem & 0.13 & 400 & \\
\hline
\end{tabular}

Since the thruster operates in a vacuum it must dissipate its heat via conduction and radiation. Conduction is the primary mode to transport the heat from the internal components to the exterior radiating surfaces. This is especially true for the inner magnet coil which is the component with the lowest maximum temperature limit, located in one of the hottest parts of the thruster. As an example this coil has two conduction paths to radiating surfaces, the inner front pole and the backpole/radiator. These paths have multiple branches and interfaces. The thermal conductance across these interfaces can strongly effect the coil's operating temperature. Therefore the design of these bolted interfaces are key features in the thermal design of the thruster.

The most important parameter in the thermal conductance of any interface is the effective contact area. Unfortunately many factors affect the calculation of this area including but not limited to; interface materials and thicknesses, surface finishes, hardness, bearing pressure, bolt sizes/patterns/spacings/torques, differential thermal distortion, etc. The effect of all of these parameters on contact area are empirically based on test results which can be somewhat dependent on the configuration of the test apparatus. Unfortunately (again) for this thruster application the vast majority of these test correlations were not developed for vacuum service. The lack of air in the microscopic voids between two surfaces further reduces thermal conductance.

In between thruster test series some pictures were taken of the backpole and radiator which clearly illustrate the nature of these contact areas as shown in Figure 10. The light areas around the bolts holes have been smoothed or burnished by the bearing force and differential thermal expansion of the interface materials. It would be very difficult if not a futile effort to measure these areas, but it could be guesstimated at 10 to $20 \%$ contact. Certainly more bolts equals more contact area but that strategy has obvious limits. 


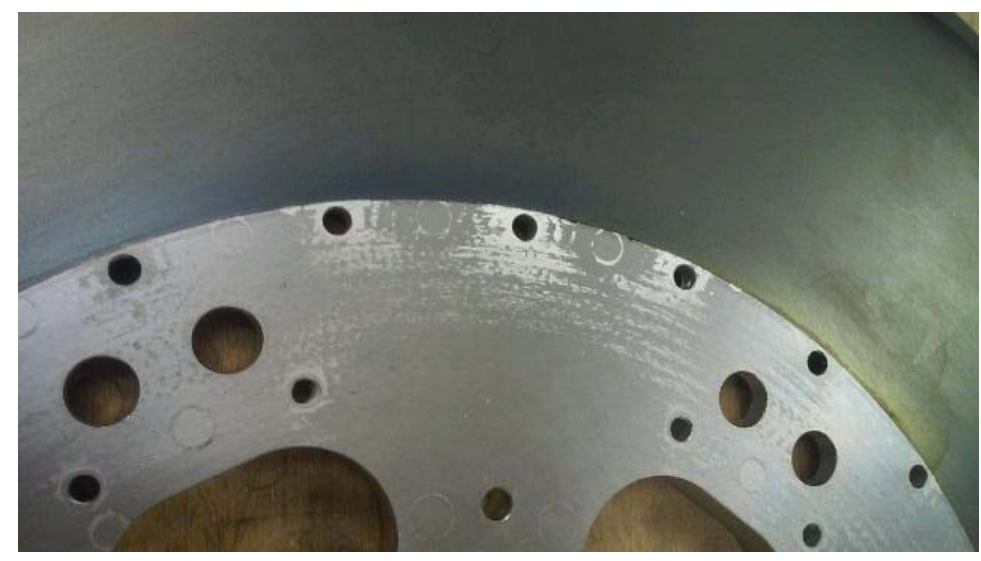

Figure 10 - Interface Contact Areas of the Radiator

Now for the good news. All of these complications associated with calculating the effective contact area can be largely avoided with the use of Thermal Interface Materials (TIM's, i.e., a gasket, foil, grease/putty). These materials to a large extent fill the micro-voids in the interface greatly increasing the effective contact area. The thermal conductivity of the gasket material and/or gap fillers plays a minor role in the interface conductance since the thickness is usually very small ( 0.005 to 0.020 inches for these applications). Thermal benefits in the form of lower operating temperatures could be obtained with the use of TIM's in select interfaces within the thruster assembly. Unfortunately the elevated operating temperatures of many thruster interfaces precludes the use of most common TIM's which are silicone based, although grafoil is one suitable exception. Consequently to date, no TIM's have been used in the design/development/testing of the HERMES thruster, but their use is under consideration pending the identification of materials appropriate for this high temperature vacuum service and component testing to demonstrate their longevity. Additionally these TIM's may provide the benefit of a softer material to reduce stress and friction at joints designed for slippage during thermal growth.

Thus due to all of the afore mentioned issues, these interface contact conductances throughout the thruster assembly become key tunable parameters to match the component-to-component delta-T's. Estimates were made for all interfaces based on values or ranges found in the literature during initial model construction. The values listed in Table 6 were derived by the conclusion of the model tuning process previously described.

\section{Table 6 - Thruster Interface Thermal Contact Conductance}

\begin{tabular}{|c|c|c|}
\hline \multicolumn{3}{|c|}{ HERMeS TDU-1 Thruster Thermal Contact Conductance Values derived from $12.5 \mathrm{~kW} 600 \mathrm{~V}$ Test Data (May 18, 2016) } \\
\hline Interface & $\begin{array}{l}\text { Conductance } \\
(\mathrm{W} / \mathrm{m} 2-\mathrm{K})\end{array}$ & Comments \\
\hline DC to Mount Ring & 1160 & Bearing force maintained with Belleville washers. \\
\hline Mount Ring to Backpole & 1240 & Slightly more then other side due to backpole fasteners. \\
\hline Mid-stem to Backpole & 3100 & \\
\hline Inner Front Pole to Mid-stem & 155 & \\
\hline Radiator to Backpole & 266 & Broad area contact over 3 bolt circles \\
\hline Inner Shield to Backpole & 620 & \\
\hline Outer Shield to Backpole & 310 & \\
\hline Inner Coil Bobbin to Backpole & 3100 & Applied on 6 circular contact areas at the bolts $\left(O D=.15^{\prime \prime}, I D=0.05^{\prime \prime}\right)$ \\
\hline Outer Coil Bobbin to Backpole & 3100 & Applied on 12 circular contact areas at the bolts (OD=.15", ID=0.05") \\
\hline Inner Coil Layers to Bobbin Flanges & 388 & \\
\hline Outer Coil Layers to Bobbin Flanges & 465 & \\
\hline Gimbal Mount Spool to Radiator & 155 & \\
\hline Gimbal Mount Spool to Thrust Stand Plate & 155 & \\
\hline Outer Guide to Backpole & 3100 & \\
\hline Outer Front Pole to Outer Guide & 3100 & \\
\hline Anode to DC & 15500 & Applied on 6 circular contact areas at the bolts (OD=.80", ID = $0.50 ")$ \\
\hline Thrust Stand Plate to Arms & $6 \mathrm{~W} / \mathrm{K}$ & $1.0 \mathrm{~W} / \mathrm{K}$ for each of 6 bolts \\
\hline All other thruster stand interfaces & 1550 & \\
\hline
\end{tabular}


In the development of Hall Effect thrusters, NASA/JPL has performed much research in the area of gas/plasma modeling [3]. Their Hall2De plasma model yields absorbed ion and electron powers over a fine mesh of the DC and inner front pole surfaces. These are mapped to the elements of the thermal model as heat loads. A summary of these plasma heat loads is presented in Table 7. Over the course of design and development of the HERMeS thruster a range of operating points have been tested and analyzed, assessing many performance criteria (Isp, peak thrust, efficiency, plume stability, component temperatures, etc.). This performance assessment has resulted in an optimized range of operating parameters referred to as the "throttle curve". To date, plasma heat loads have been generated for the minimum and maximum power levels of that curve $(9.4 \mathrm{~kW}, 300 \mathrm{~V}$ and $12.5 \mathrm{~kW}, 600 \mathrm{~V})$. Plasma model updates and revisions have been produced to improve the thermal model correlation with thruster test data.

As with the other tunable parameters in the thermal model there are some elements of uncertainty in the calculation of the plasma heat loads. A good match of test and model temperatures required the use of scale factors applied to these heat load mappings. This not only facilitates tuning of the thermal model to match test temperatures, but ultimately provides feedback for refinement of the plasma model. As the plasma model matures with improvements in the simulations of gas ionization and magnetic shielding these scale factors will be reduced and/or eliminated. This work continues [3].

\section{Table 7 - Plasma Heating Predictions}

\begin{tabular}{|c|c|c|c|c|c|c|c|c|}
\hline & & & \multicolumn{3}{|c|}{ Plasma Heating (W) } & \\
Thruster & Magnetic & & Discharge & & & & & Total \\
Power & Field & & Voltage & DC Outer & DC Inner & & Inner & Heat \\
(W) & Topology & Fuild & (V) & Wall & Wall & Anode & Frt Pole & (W) \\
\hline 12.5 & II & 2FLD & 600 & 616 & 440 & 496 & 181 & 1733 \\
\hline
\end{tabular}

\section{Correlation Results}

Having developed a thermal model representing all heat transfer pathways throughout the thruster and its environment, it seemed a relatively simple task to apply the calculated heat loads and make adjustments to the tuning parameters (interface thermal conductance and surface emittance) to match the test temperatures. However, regardless of the adjustments made the model significantly over predicted the test temperatures, even with prefect surface emittance $(\varepsilon=1.0)$ and excessively high rates of interface conductance. Therefore the heat loads would also require some adjustments. From the heat load summary (Table 3) the plasma loads on the anode, DC and inner pole constitute $\sim 93 \%$ of the thruster's predicted heat loads. Scale factors were then applied to these heat load mappings in order to match the test temperatures. This effectively reversed the correlation process meaning the test temperatures could be used to predict the heat loads, within the accuracy of heat conduction and radiation parameters in the model. With high degrees of confidence in the test temperatures and the measured emittance of the thruster exterior surfaces the only remaining tuning parameter was the interface conductances. Additionally the component test temperatures were used to tune the interface conductances to match the $\Delta \mathrm{T}$ 's throughout the thruster assembly. The validity of this approach is explained as follows.

To calculate the total heat load on the thruster we start with the simple premise for steady state conditions;

$$
\text { Heat in }=\text { Heat out }
$$

Thus the heat generated within the thruster equals the heat rejected by the thruster. The thermal model defines all conductive and radiative heat pathways to its environment (i.e., Heat out) as a function of temperature (primarily external surface temperatures). Therefore the total heat generated within the thruster can be determined by an iterative solution (adjusting the scale factors on plasma heating) to match the test temperatures of all external heat rejecting surfaces of the thruster. 
The thermal model was correlated at the specified optimum throttle point $(12.5 \mathrm{~kW}, 600 \mathrm{~V})$. A profile plot of the model temperatrures are shown in Figure 11. The most recent set of plasma heat loads for these operating conditions (see Table 7) were used along with scale factors (shown in Table 3) on the DC, anode and inner front pole to match the test temperatures. This yielded a total plasma heat load of $849 \mathrm{~W}$ which is $\sim 6.8 \%$ of thruster discharge power. This is low compared to data compiled from previous NASA development Hall thrusters (10 to $25 \%$ ). However data from these older thrusters is limited, not validated and the sample set is small.

Knowing the magnitude of the plasma heating solves half the puzzle, allowing the plasma modeling to concentrate on predicting the heat distributions. Recent changes to the thruster grounding scheme and discharge voltage have significantly reduced the plasma heating compared to prior test results.

The three original parameters planned for model correlation represent the heat generated within the thruster (predominately plasma heating), the heat conducted through the thruster (interface contact conductances) and the heat rejected by the thruster (exterior surface emittances). Having measured the surface emittance of the actual thruster materials/surfaces (see Figures $8 \&$ 9) reduces these variables down to two, thruster heating \& contact conductances. Then using the test temperatures to solve for thruster heating effectively leaves the interface conductance as the lone tuning parameter. For a specified thruster configuration (i.e., exterior surface geometry) the known emittance values allows the model to define heat rejection as a function of the surface temperatures. This greatly reduced the iterative tuning process to determine the total heat generated within the thruster, being plasma and coil heating. With coil heating calculated from the measured test currents, the magnitude of the plasma heating was found by deduction. This was implementted by the use of the afore mentioned plasma scale factors. Of course, the distribution of this plasma heating across the DC and inner front pole must be determined by the Hall2De plasma model. However the high thermal conductivities of the anode and front pole (metals) will tend to minimize any thermal gradients induced by potentially skewed plasma heat load mappings.

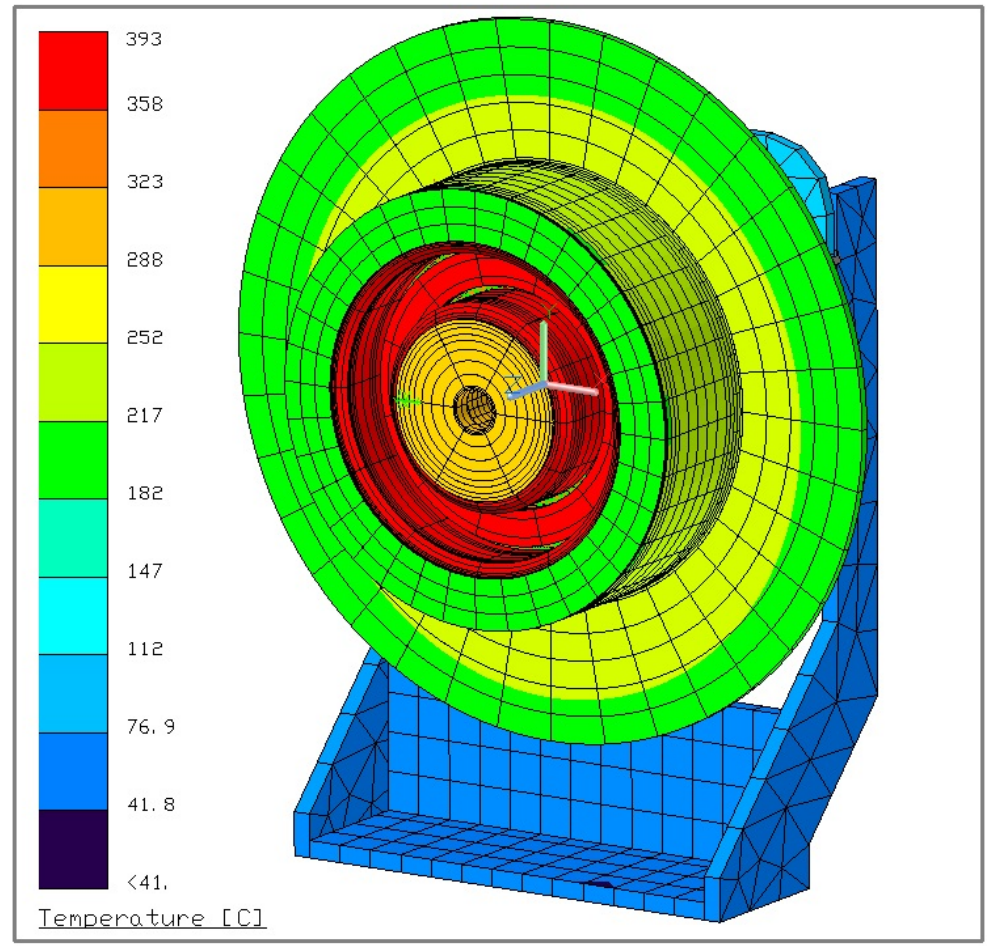

\section{Figure 11 - Temperature Profile of Correlated Thermal Model $(12.5 \mathrm{~kW} / 600 \mathrm{~V})$}


A more detailed tabulation of the model correlation is presented in Table 8. The colored rows represent components with multiple TC's with their average temperatures in the next column. The TC's have a reported error band of $+/-5 \mathrm{C}$ at $500 \mathrm{C}$. Thus the correlation or model tuning process was considered complete when the test-tomodel $\Delta \mathrm{T}$ 's were reduced to $<10 \mathrm{C}$. The model was conservatively tuned to yield most component temperatures from 0 to $10 \mathrm{C}$ warmer than test data. All thruster components display thermal margins under their respective temperature limits. Table 8 lists a direct comparison of test versus model temperatures.

\section{Table 8 - Tabulation of Test and Model Temperatures (4/29/2016 Test Data)}

\begin{tabular}{|c|c|c|c|c|c|c|c|}
\hline Component & $\begin{array}{c}\text { Data } \\
\text { File } \\
\text { Column }\end{array}$ & $\begin{array}{c}12.5 \mathrm{~kW} \\
600 \mathrm{~V} \\
\text { Test Temps } \\
\text { (C) }\end{array}$ & $\begin{array}{c}\text { Avg } \\
\text { Test } \\
\text { Temps } \\
\text { (C) }\end{array}$ & $\begin{array}{c}12.5 \mathrm{~kW} \\
600 \mathrm{~V} \\
(\mathrm{DC}=0.52, \\
\text { Pole }=0.23) \\
\text { Model } \\
\text { Temps }(\mathrm{C})\end{array}$ & $\begin{array}{l}\text { Avg } \\
\text { Model } \\
\text { Temps } \\
\text { (C) }\end{array}$ & $\begin{array}{c}\text { Test } \\
\text { to } \\
\text { Model } \\
\Delta \mathrm{T} \\
\text { (C) }\end{array}$ & Comments \\
\hline DC outer wall Dwnstrm $30 \mathrm{C}$ & $\mathrm{BI}$ & 404 & & 383 & & & \\
\hline DC outer wall Upstrm $30 c$ & $\mathrm{Cl}$ & 343 & & 353 & & & \\
\hline DC inner wall Upstrm $3 O C$ & BJ & 341 & & 353 & & & \\
\hline DC innerwall Dwnstrm $3 O C$ & $\mathrm{CH}$ & 364 & 363 & 389 & 370 & -7 & Wall te mps. \\
\hline DC Base 6 Oclock & BK & 328 & & 344 & & & \\
\hline DC Base 12 Oclock & CK & 357 & 343 & 344 & 344 & -2 & Base temp. \\
\hline Outer Coil-Dwnstrm & $\mathrm{BH}$ & 271 & & 274 & & & SS containment shield. \\
\hline Outer Coil- Upstrm & $\mathrm{CA}$ & 272 & 272 & 273 & 274 & -2 & SS containment shield. \\
\hline Inner Coil - Upstrm & $\mathrm{BX}$ & 393 & & 384 & & & SS containment shield. \\
\hline Inner Coil - Dwnstrm & CE & 380 & 387 & 390 & 387 & -1 & SS containment shield. \\
\hline DC Mount Ring OD & BL & 308 & & 314 & & & \\
\hline DC Mount Ring-ID & CJ & 319 & 314 & 318 & 316 & -3 & \\
\hline Radiator $O D 12 \mathrm{OC}$ & $\mathrm{BO}$ & 86 & & 213 & & & Errone ous test val ue. \\
\hline Radiator OD 6 OC & $\mathrm{BP}$ & 178 & & 213 & & & \\
\hline Radiator ID & $\mathrm{CB}$ & 260 & 219 & 243 & 223 & -4 & \\
\hline Back Pole Near OD & $B Z$ & 267 & & 246 & & & \\
\hline Backpole Near DC & $B R$ & 278 & & 295 & & & \\
\hline Backpole Near ID & $\mathrm{CC}$ & 299 & 281 & 307 & 283 & -1 & \\
\hline Spool Mount Front Flange & $B Q$ & 186 & & 183 & & & \\
\hline Spool Mount Rear Flange & $\mathrm{BN}$ & 106 & 146 & 109 & 146 & 0 & \\
\hline Inner Front Pole $60 \mathrm{c}$ & BU & 309 & & 310 & & & \\
\hline Inner Front Pole $12 \mathrm{OC}$ & CG & 306 & 308 & 310 & 310 & -3 & \\
\hline Outer Screen & $B F$ & 285 & & 284 & & 1 & \\
\hline Inner Screen & $C D$ & 322 & & 322 & & 0 & \\
\hline Outer Front Pole-Inside & $B G$ & 216 & & 212 & & 4 & \\
\hline Outer Guide - Middle & BM & 221 & & 228 & & -7 & \\
\hline Thrust Stand Base & BV & 42 & & 42 & & N/A & Used as thermal BC. \\
\hline Thrust Stand Arm & BY & 73 & & 68 & & 5 & \\
\hline Midstem & BS & 323 & & 321 & & 2 & \\
\hline Back Cover Plate & BT & 113 & & 114 & & -1 & \\
\hline Inner Magnet Current (A) & V & 3.38 & & 3.38 & & & \\
\hline Outer Magnet Current (A) & $\mathrm{N}$ & 2.82 & & 2.82 & & & \\
\hline
\end{tabular}

Despite achieving a good overall model correlation with test temperatures some discrepencies still exist. Contrary to test results the model predicts the inner wall of the DC to be hotter than the outer wall. The contact conductance at the base of the DC provides impartial cooling to both walls. Also the opposing walls of the DC have geometric symmetry promoting nearly equivalent view factors and the same optical emittance. Thus contact conductance at the DC mounting surface and material emittance parameters cannot bias the wall temperatures. This leaves the plasma heat loads as the only tuning parameter that can affect DC wall temperatures. As noted earlier the plasma heating is a very complex process of particle ionization and acceleration driven by E-fields and magnetic shielding driven by B-fields. Not surprisingly, many operational parameters (discharge voltage and current, B-field intensity, electrical grounding, etc.) of the thruster effect the magnitude and distribution of these heat loads. Work continues to improve the plasma model predictions in these areas [3]. 
One other area of disagreement between test and model temperatures was the inner and outer magnet coils. Although significant effort went into calculating the integrated thermal conductance of the potted coil assemblies (see Figure 2 and Table 2), test results show far less conductance (factor of 10). The cause of this is believed to be cracking of the ceramic potting compound throughout the windings due to the elevated operating temperatures and the 20 to 1 differential in material CTE's (copper $\rightarrow 16.6 \times 10-6$ in/in-C, ceramic potting $\rightarrow 0.8 \times 10-6$ in/in-C). Another baffling anomaly was the reverse axial temperature gradient measured in the inner coil. The upstream end of the coil/bobbin which is mounted to the backpole (i.e., heat sink) was hotter than the downstream end. One possible explanation is separation between the windings and the bobbin flange as the copper bobbin expands. This was also seen during previous thruster testing.

The HERMeS project has carried plans for detailed thermal testing of these coils but other priorities have repeatedly postponed these tests. With thruster development testing nearing completion, the thermal engineer may now shift his attention to resolving these anomalies in the heat dissipation of the coils. To further reduce coil temperatures the mounting interface of these coils is a good candidate for the use of TIM's (thermal gaskets).

\section{On-Orbit Mission Simulations}

In addition to assessing design/development issues of the HERMeS thruster, the now correlated thermal model is the primary means to show compliance with mission thermal and some power (environmental) requirements.

Therefore, in an effort to better quantify thermal environmental extremes that the HERMeS thruster may encounter during a mission, several orbital scenarios were analyzed based on relevant ARRM environment envelopes. It is expected that ARRM will require a thruster capable of operating over a heliocentric range of 0.8 to 1.9 Astronautical Units (AU). Of most concern are the maximum operating temperatrures of the thruster, as maximum material temperature limits are thermal design drivers. Additionally, the amount of heat radiated from various thruster surfaces to space is pertinent information to consider for spacecraft integration as the heat radiated will drive thruster mounting interface and orientation considerations. That being said, a sun facing thruster (anode to sun) at 0.8AU, was analyzed to bound the hot extreme environment, and a deep space simulation (absence of external radiation heat sources) was analyzed to bound the cold extreme environment. These are listed in Table 9. This cold extreme environment was assumed to represent a 1.9AU case at which the thruster could be oriented in such a way, with respect to the spacecraft, that it would not have any view factor to the sun or to planetary radiation and albedo. While the cold case was not a maximum temperature driving case, it was analyzed for the purposes of gauging the effect of the presence of solar heating at $0.8 \mathrm{AU}$.

\section{Table 9 - Thruster Orbital Case and Descriptions}

\begin{tabular}{|c|c|}
\hline Orbital Case & Description \\
\hline $0.8 \mathrm{AU}$ & $\bullet 0.8$ AU Solar Orbit \\
& - Solar Inertial \\
& (anode sun \\
& facing) \\
& - Spacecraft \\
& simulation \\
& surface \\
\hline Deep Space & - No orbital \\
& trajectory \\
& No spacecraft \\
& simulation \\
& surface \\
\hline
\end{tabular}

19

American Institute of Aeronautics and Astronautics 
To mimic thruster proximity to an adjacent spacecraft the orbital case was run with a 2 meter radius spacecraft simulation surface set 0.5 meters away from the thruster, as shown in Figure 12, represented as nearly adiabatic. In reality, thruster-to-spacecraft radiative heat transfer will be much more intricate as there will be more complex geometrical shapes, angles, and material properties influencing view factors. This surface was given a zero emissivity and a nearly zero absorbtivity (set to 0.01 , for the purposes preventing an alpha over epsilon ratio value of zero). These optical properties preclude solar absorbtion and solar emittance of the surface, thereby prohibiting the surface from gaining or losing heat, rendering it nearly adiabatic. The thermal worst case operating conditions of the thruster were used for these orbital simlations.

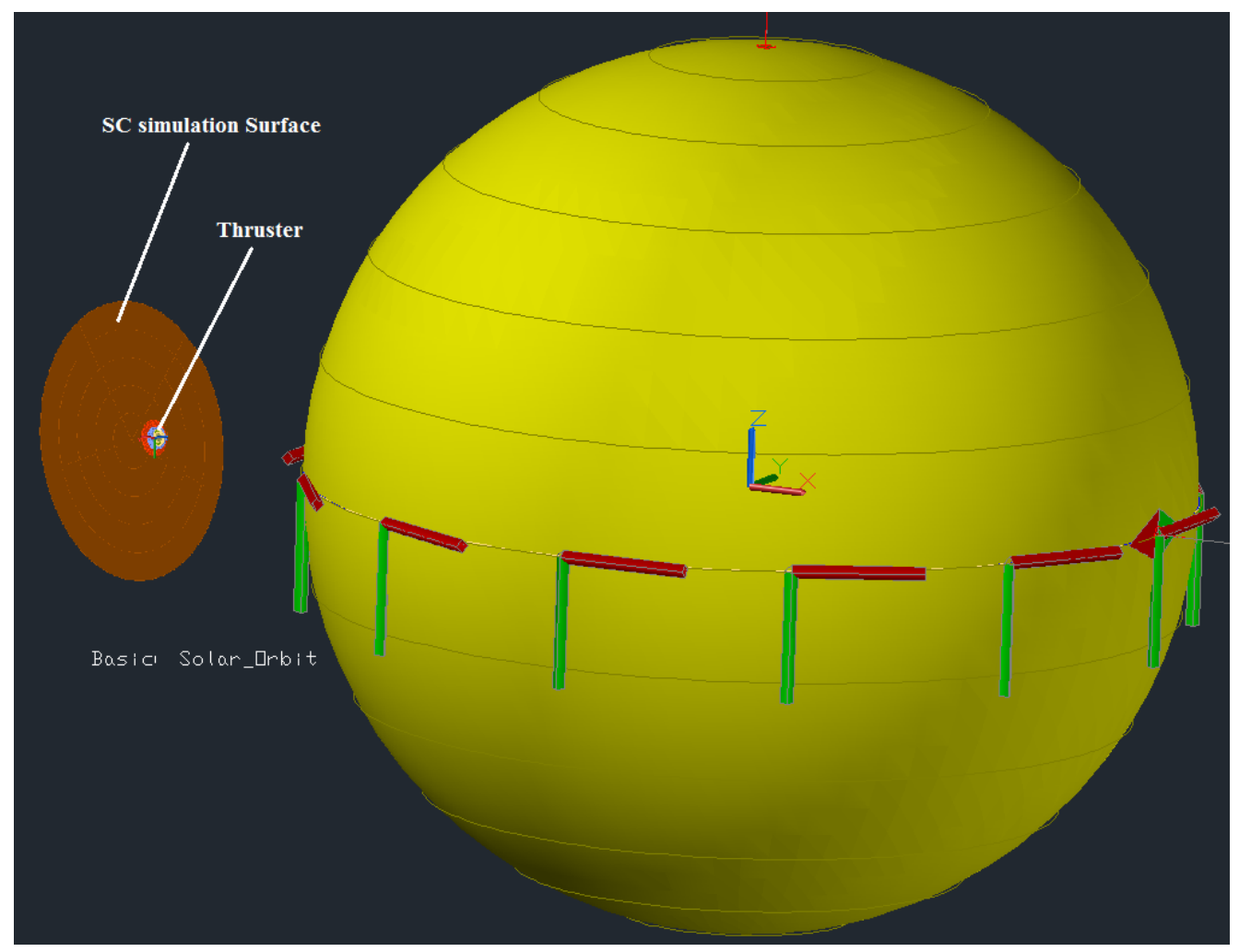

\section{Figure 12 - Thruster and Spacecraft Simulator in Solar Orbit (Aft Sun-Facing)}

While the hot environmental case results reflect an adiabatic spacecraft surface as described above, similar cases were run with varying combinations of emissivity and absorbtivity resulting in minimal changes to thruster component temperatures and heat rejection to space (on the order of $<2$ degrees Celsius and $<5$ Watts, respectively). This would suggest that the thermal effects of the presence of a spacecraft near a thruster are more dependent on additional factors, not examined here, like higher fidelity modeling of the mounting mechanism and entire host spacecraft.

Table 10 contains the maximum temperatures of each thruster component and the thruster radiated heat to space for each component for the hot environmental case. The temperature differences between the hot and cold cases (only the hot case data is presented as it pertains to the max temperature limits) indicates that the majority of the thruster heating is self generated, and not from solar radiation. 


\section{Table 10 - Minimum and Maximum Temperature and Radiated Heat for 0.8AU (Aft Sun-Facing) Thruster/SC Simulator}

\begin{tabular}{|c|c|c|c|c|}
\hline \multirow[b]{2}{*}{ Thruster Component } & \multicolumn{3}{|c|}{ Temperatures $\left({ }^{\circ} \mathrm{C}\right)$} & \multirow{2}{*}{$\begin{array}{c}\text { Thruster } \\
\text { Radiated Heat } \\
\text { to Space (Watts) }\end{array}$} \\
\hline & Min & Max & Delta & \\
\hline Anode & 508 & 582 & 74 & 100.88 \\
\hline Backpole & 369 & 429 & 60 & 17.55 \\
\hline Chamber Mounts & 460 & 460 & 0 & \\
\hline Discharge Chamber & 497 & 570 & 73 & 652.86 \\
\hline Discharge Chamber Ring & 451 & 460 & 9 & \\
\hline Gimbal Mounting Ring & 255 & 349 & 94 & 322.36 \\
\hline Inner Coil Bobbin & 436 & 473 & 37 & \\
\hline Inner Magnet Coil & 470 & 498 & 28 & \\
\hline Inner Core & 443 & 459 & 16 & 4.94 \\
\hline Inner Front Pole & 454 & 476 & 22 & 171.3 \\
\hline Inner Shield & 486 & 499 & 13 & \\
\hline Outer Coil Bobbin & 379 & 392 & 13 & \\
\hline Outer Magnet Coil & 387 & 393 & 6 & \\
\hline Outer Front Pole & 270 & 272 & 2 & 152.95 \\
\hline Outer Shield & 451 & 458 & 7 & 0.12 \\
\hline Outer Support Ring & 290 & 320 & 30 & 224.64 \\
\hline Radiator & 333 & 400 & 67 & 829.16 \\
\hline Rear Screen & 209 & 209 & 0 & 22.11 \\
\hline & & & Total & 2498.87 \\
\hline
\end{tabular}

\section{Conclusion}

Having completed an extensive test campaign successfully demonstrating the high Isp performance with thermal margins and reduced erosion characteristics of the HERMeS design, the development team has high expectations proceeding into the final testing stages to assess the durability and longevity of the HERMeS thruster. These tests designed to quantify the thruster's wear characteristics will identify any areas of the design that may need revision to achieve the long duration operational life required for ARRM and ensuing NASA interplanetary missions. 


\section{References}

[1] D. T. Jacobson, J. John, H. Kamhawi and D. H. Manzella, “An Overview of Hall Thruster Development at NASA's John H. Glenn Research Center", 41 ${ }^{\text {st }}$ AIAA/ASME/SAE/ASEE Joint Propulsion Conference, 10-13 July, 2005, Tucson, Arizona, AIAA 2005-4242.

[2] John. T. Yim, Lauren. K. Clayman and L. C. Chang, "Thermal Modeling and Analysis of NASA High Power Hall Thrusters", JANNAF 2013 Conference, JANNAF 2013-3005.

[3] Mikellides, I. G., Lopez Ortega, A., Hofer, R. R., Polk, J. E., Kamhawi, H., Yim, J. T., and Myers, J., "Hall2de Simulations of a 12.5-kW Magnetically Shielded Hall Thruster for the NASA Solar Electric Propulsion Technology Demonstration Mission", Presented at the 34th International Electric Propulsion Conference, IEPC-2015-254, Kobe, Japan, July 4-10, 2015.

[4] Thermal Desktop, C\&R Technologies

[5] Hani Kamhawi, Wensheng Huang, Thomas Haag, John Yim, Daniel Herman, Peter Peterson, George Williams, James Gilland, Richard Hofer and Ioannis Mikellides, "Performance, Facility Pressure Effects, and Stability Characterization Tests of NASA's Hall Effect Rocket with Magnetic Shielding Thruster", 52 nd AIAA/SAE/ASEE Joint Propulsion Conference, Salt Lake City, Utah, July 25-27, 2016.

\section{Acknowledgments}

The authors would like to acknowledge the participation of the entire project team for their contributions to the development of the HERMeS thruster. They are identified here with their organization in their functional roles.

Daniel Herman/GRC/Project Manager - Thruster Commercialization \& Mission Integration

Timothy Smith/GRC/Project Manager - Thruster Development

Richard Hofer/JPL/Hall Thruster Development Lead

Wensheng Huang/GRC/Hall Thruster Diagnostics Researcher

Pete Peterson/GRC/ Propulsion Systems Senior Research Engineer

Ioannis Mikellides/JPL/Plasma Analyst

Thomas Haag/GRC/Hall Thruster Fabrication \& Test Setup Engineer

George Williams/OAI/Hall Thruster Testing

Christopher Griffiths/Vantage/CAD Mechanical Designer

Dale Robinson/Vantage/CAD Mechanical Designer

Kevin Blake/GRC/Machinist \& Thruster Fabrication Technician

Michael Sekerak/JPL/Hall Thruster Testing

James Polk/JPL/Hall Thruster Research \& Thermal Analyst

Li Chang/GRC/Structural Analyst

Rohit Shastry/GRC/Hall Thruster Plasma Diagnostics

Timothy Verhey/GRC/Cathode Reseach \& Development

Robert Thomas/GRC/ Hall Thruster Diagnostics Researcher

Benjamin Jorns/JPL/Propulsion Systems Researcher

Steve Snyder/JPL/ Propulsion Systems Researcher

Daniel Goebel/JPL/ Cathode Development Researcher

Bradley Gilliam/Zin Technologies/Thruster Documentation

James Gilland/OAI/Plasma \& Backsputter Modeling

Michael Swiatek/GRC/Test Facilities Engineer 


\section{Appendix A}

\section{Derivation of Temperature Dependent Emissivities \\ (provided courtesy of Donald Jaworske of NASA/GRC)}

Each sample surface was directionally illuminated and the reflectance from the surface was hemispherically detected at numerous wavelengths between 2 and 25 microns utilizing a Surface Optics Corporation SOC-400t portable infrared reflectometer. Reflectance as a function of wavelength, averaged over 128 scans, was obtained for each sample surface. A single emittance value was derived from the spectral reflectance values by subtracting the reflectance values from unity and weighting each spectral emittance value with respect to the black body spectrum for a given temperature. The area under this weighted curve divided by the area under the black body curve provided a single emissivity value at that temperature. This process was repeated for numerous black body spectra representing the temperature range of interest. Then, emittance was plotted as a function of temperature. 